\title{
Activity of Spent Coffee Ground Cinnamates against Wood-decaying Fungi in vitro
}

\begin{abstract}
Aitor Barbero-López, ${ }^{\mathrm{a}, *}$ Antonio Ochoa-Retamero, ${ }^{\mathrm{a}}$ Yeray López-Gómez, ${ }^{\mathrm{a}}$ Teemu Vilppo, ${ }^{\mathrm{b}}$ Martti Venäläinen, ${ }^{\mathrm{c}}$ Anu Lavola, ${ }^{\mathrm{d}}$ Riitta Julkunen-Tiitto, ${ }^{\mathrm{d}}$ and Antti Haapala ${ }^{\mathrm{a}, \mathrm{b}}$

Fungi and microbes can remarkably degrade the appearance and durability of organic materials, such as wood. The inhibitory effects of natural phenolics may offer more sustainable alternatives to preserve wood than the toxic biocides that are currently used. Although pure caffeine has been proven to have antibacterial properties, the applicability of spent coffee in wood preservation has not been determined. This work conducted in vitro tests with three brown rot and one white rot fungi and demonstrated the potential of spent coffee-derived cinnamates, analyzed with high-performance liquid chromatography, as antimicrobial agents. Spent coffee at concentrations of $1 \%$ and above in the growing media caused significant growth suppression of all of the fungi. This was not only because of the caffeine, but also the other chemicals present in the residue extracts, which demonstrated that spent coffee could be used as a source of green chemicals in wood preservative formulations.
\end{abstract}

Keywords: Biorefining; Preservatives; Secondary metabolites; Wood decay; Wood preservation

Contact information: a: School of Forest Sciences, University of Eastern Finland, FI-80101, Finland; $b$ : Department of Applied Physics, University of Eastern Finland, FI-70211, Finland; c: Natural Resources Institute Finland, FI-58450 Punkaharju, Finland; d: Department of Environmental and Biological Sciences, University of Eastern Finland, FI-80101, Finland;

* Corresponding author: Aitor.Barberolopez@uef.fi

\section{INTRODUCTION}

Increasingly strict legislation on toxic wood preservatives is driving the development of green chemicals for wood. The use of many wood preservatives is limited or banned, as chromated copper arsenate (Mohajerani et al. 2018). Other types of metal salt, borate, and creosote products are still used, although constant pressure is applied by the national chemicals agencies for less toxic substitutes. More limitations for wood preservatives can be expected, as they belong to a class of so called emerging pollutants, together with several pesticides and pharmaceuticals (Geissen et al. 2015).

Green chemicals that protect wood from decay and pathogens, while also maintaining a low environmental impact (Ding et al. 2017), are sought from plant extracts. Examples of these chemicals are the polyphenols, such as condensed tannins (Anttila et al. 2013) and stilbenes (Lu et al. 2016), known antifungals with some commercial products already on the market. Novel and interesting sources for potential antifungals can be found in industrial side-streams, such as coffee refining (Arora and Ohlan 1997; Acevedo et al. 2013). The phenolics and alkaloids (e.g. caffeine) in the side-streams of coffee refining have no competing industrial use. Mazela et al. (2016) recently verified the antifungal activity of purified caffeine in a wood preservation setting, while Lekounougou et al. (2007) demonstrated its antifungal properties against some wood-decaying fungi. Contradicting results have been found for bacteria; Sant'Anna et al. (2017) found that spent 
coffee grounds (SCGs) does not inhibit the growth of different foodborne pathogenic bacteria and phytopathogenic fungi, while Sousa et al. (2015) suppressed different diseasecausing bacteria and yeasts using spent coffee.

Despite several interesting functionalities of SCGs, the limited availability of the raw material often renders their valorization economically unattractive. This has been shown in the case of biodiesel production from SCGs (Kookos 2018), but obviously a different outcome can be achieved if the end product has significantly higher market value or lower cost of production. In most of the soluble coffee producing industries, the waste is collected by specialized agencies, which sell the residues for different purposes (i.e. composting, gardening, bioenergy production, mushroom growth) but for commercial or household SCGs there is no established recovery and recycling system. Present studies focus in different aspects of fresh and spent coffee. Their components have been extensively analyzed (Mullen et al. 2013; Monente et al. 2015). Contemporary studies concerning coffee have focused mostly on health implications (Koloverou et al. 2015), land use, and climate issues (Ricketts et al. 2004). Studies on the revalorization of spent coffee grounds have focused on energy applications (Santos et al. 2017) and food supplements (Panzella et al. 2017). These studies and the recent reviews of this topic (Kourmentza et al. 2018; Mata et al. 2018) do not address the potential of spent coffee-derived chemical components as a potential resource for antifungal chemicals with applications, e.g. in wood preservation.

In this paper we present for the first time the capacity of spent coffee as a green alternative to reduce wood-decaying fungi growth. We also characterized fresh and spent coffee grounds in terms of the chemical composition and assessed the efficiency of the extracted chemical mixes against common wood-decaying fungi. Our aim was to determine if the waste generated from coffee brewing has potential for use as a feedstock in chemical extraction and if its functionality can be utilized in wood preservation or as an antifungal in a more general context.

\section{EXPERIMENTAL}

Fresh and spent medium-roast coffee grounds (100\% Coffea arabica) were tested by extracting 50-g batches of coffee grounds in $1 \mathrm{~L}$ of boiling Milli-Q water (Merck KGaA, Darmstadt, Germany) for 45 min to obtain a concentrated hot water extract with a low number of volatile components. After extraction, the solids were removed with either a fine sieve or 30- $\mu \mathrm{m}$ filter. The growth media included $4 \%$ malt powder and $2 \%$ agar, along with $1 \%, 2 \%$, or $5 \%$ sieved spent coffee extracts (SCEs) (w/w), $1 \%$ filtered SCEs, or $1 \%$ fresh coffee. Reference media were made with $1.6 \%$ copper-based preservative (Celcure C4, Koppers Inc., Pittsburgh, PA, USA), 4\% malt, and 2\% agar to have an industrial NTR (Nordiska Träskyddsrådet) AB-class standard capable preservative as reference. The commercial copper-based wood preservative contained copper(II) carbonate (17\%), ethanolamine $(<35 \%)$, benzalkonium chloride $(4.75 \%)$, cyproconazol $(0.096 \%)$, sodium nitrite $(<5 \%)$, and polyethoxylated tallow amine $(<5 \%)$.

The chemical composition of the SCEs was analyzed in detail with an HP 1100 Series LC-system (Agilent Technologies, Palo Alto, CA, USA) equipped with a diode array detector, where the reverse-phase separation was performed on a Hypersil ODS (Thermo Fisher Scientific, Waltham, MA, USA) with a RP C18 column (Thermo Fisher Scientific, Waltham, MA, USA) with the dimensions $75 \mathrm{~mm} \times 4.6 \mathrm{~mm}$. Phenols were separated by 
gradient elution using aqueous $1.5 \%$ tetrahydrofuran with $0.25 \%$ orthophosphoric acid (A) and methanol (B) as eluents. The following elution gradient was used: 0 min to 5 min with $100 \%$ A, 5 min to 10 min with $85 \%$ A and $15 \%$ B, 10 min to 20 min with $70 \%$ A and $30 \%$ B, 20 min to 60 min with $50 \% \mathrm{~A}$ and $50 \% \mathrm{~B}$, and 60 min to 65 min with $100 \% \mathrm{~B}$. The flow rate was $2 \mathrm{~mL} / \mathrm{min}$, the column temperature was $30^{\circ} \mathrm{C}$, and the injection volume was 20 $\mu \mathrm{L}$. The compounds were detected at a wavelength of $270 \mathrm{~nm}$, and the tentative identification was based on the retention time, UV spectra of the compounds, and the literature. The quantification of the compounds was based on the response factors specific to the standard compounds. Standards provided with the chemicals purchased from SigmaAldrich (Sigma-Aldrich Finland Oy, Helsinki, Finland) were used in the identification and quantification of the components in the coffee samples: chlorogenic acid for all of the chlorogenic acid derivatives; ferulic acid; $p$-OH-cinnamic acid for the $p$-OH-cinnamic acid derivatives; cinnamic acid for the caffeic acid derivatives; protocatechuic acid for the protocatechuic acid derivative; and caffeine.

The growth reduction efficiency of the SCEs was tested in vitro with three brown rot fungal strains (Coniophora puteana BAM 112, Gloeophyllum trabeum BAM 115, and Rhodonia (Poria) placenta BAM 113) and a white rot fungal strain (Trametes versicolor BAM 116) obtained from the Federal Institute for Materials Research and Testing (BAM, Berlin, Germany). Fungal hyphae plug measuring $0.28 \mathrm{~cm}^{2}$ were placed in a petri dish $(\varnothing$ $90 \mathrm{~mm}$ ) and incubated with no light at $22{ }^{\circ} \mathrm{C} \pm 2{ }^{\circ} \mathrm{C}$ and $70 \%$ relative humidity between 9 and 11 days, when the mycelium of the control fungi reached the edge of the dish. Between six and ten replicates were prepared, depending on the species and its growth variability. The growth rate inhibition was measured by following the method from Chang et al. (1999). The inhibition rate of the fungal growth with the addition of extracts in the growth media was assessed according to Eq. 1,

$$
\text { Inhibition }(\%)=(1-(A T-I A) /(A C-I A)) \times 100
$$

where $A T$ is the fungal area in the experimental sample $\left(\mathrm{cm}^{2}\right), A C$ is the fungal area in the control sample $\left(\mathrm{cm}^{2}\right)$, and $I A$ is the size of the inoculated plug $\left(\mathrm{cm}^{2}\right)$. Pictures of the petri dish were taken with the same set up as explained in Ancin-Murguzur et al. (2018).

The statistical significance of the coffee treatments was determined using Fisher's least significant difference test with the least significant difference as the post-hoc for the analysis of variance using the software SPSS Statistics 23 (IBM, New York, USA).

\section{RESULTS AND DISCUSSION}

Most of the water-soluble, low molecular weight components, including sugars, caffeine, and other polar compounds like phenolic compounds, were removed during the first extraction (coffee brewing), which left less soluble components in the SCEs. Volatile components and large molecular weight components, like tannins and carbohydrates, were not detected. The amount of caffeine decreased significantly between the fresh coffee and SCEs, and the concentrations of other components were also noticeably lower.

The phytochemical profiles (high performance liquid chromatography (HPLC)fingerprints) of the samples were comparable. Seventy and 75 different components above the detection limit at $270 \mathrm{~nm}$ were separated from the SCEs made from fresh coffee and the filtered fresh coffee sample, respectively. In the SCEs from the spent coffee grounds, 
the number of components was consistent between the samples and was approximately half of that in the fresh coffee samples (Table 1).

Table 1. Concentrations of the Compounds in Different Liquid Coffee Samples Analyzed by HPLC

\begin{tabular}{|c|c|c|c|c|c|}
\hline Compound & $\begin{array}{c}\text { Retention } \\
\text { Time } \\
\text { (min) }\end{array}$ & $\begin{array}{l}\text { Fresh } \\
\text { Coffee } \\
\text { (mg/L) }\end{array}$ & $\begin{array}{c}\text { Filtered } \\
\text { Fresh } \\
\text { Coffee } \\
(\mathrm{mg} / \mathrm{L})\end{array}$ & $\begin{array}{l}\text { SCEs } \\
(\mathrm{mg} / \mathrm{L})\end{array}$ & $\begin{array}{l}\text { Filtered SCEs } \\
\quad(\mathrm{mg} / \mathrm{L})\end{array}$ \\
\hline Protocatechuic acid der. & 4.0 & - & - & 2.7 & 2.1 \\
\hline Chlorogenic acid der. 1 & 4.1 & 39.3 & 33.6 & - & - \\
\hline Chlorogenic acid der. 2 & 4.6 & 26.9 & 22.9 & 3.9 & 4.0 \\
\hline Chlorogenic acid der. 3 & 5.3 & 7.5 & 6.3 & - & - \\
\hline Caffeine (alkaloid) & 6.0 & 1104.1 & 934.3 & 31.7 & 31.0 \\
\hline Neochlorogenic acid & 6.6 & 733.8 & 613.9 & 60.8 & 64.9 \\
\hline Chlorogenic acid der. 4 & 8.6 & 2.7 & 2.3 & 1.2 & - \\
\hline p-OH-Cinnamic acid der. 1 & 9.1 & 7.5 & 6.1 & 0.8 & 0.7 \\
\hline Chlorogenic acid der. 5 & 10.3 & 175.8 & 143.9 & 17.7 & 19.2 \\
\hline Chlorogenic acid & 10.8 & 1138.7 & 949.6 & 97.9 & 102.3 \\
\hline Chlorogenic acid der. 6 & 11.5 & 638.7 & 526.1 & 58.2 & 58.2 \\
\hline p-OH-Cinnamic acid der. 2 & 13.3 & 5.0 & 4.9 & 0.6 & - \\
\hline p-OH-Cinnamic acid der. 3 & 13.6 & 7.5 & 5.0 & 0.5 & 0.3 \\
\hline Chlorogenic acid der. 7 & 14.0 & 18.6 & 14.9 & 0.8 & 0.8 \\
\hline Ferulic acid & 14.4 & 120.1 & 99.1 & 11.4 & 11.4 \\
\hline Chlorogenic acid der. 8 & 15.3 & 67.6 & 56.0 & 7.2 & 8.9 \\
\hline Caffeic acid der. 1 & 16.7 & 1.4 & 1.4 & - & - \\
\hline Caffeic acid der. 2 & 16.9 & 3.7 & 3.1 & - & - \\
\hline Chlorogenic acid der. 9 & 18.6 & 4.3 & 3.0 & - & - \\
\hline Chlorogenic acid der. 10 & 20.4 & 2.1 & 2.4 & - & - \\
\hline Chlorogenic acid der. 11 & 20.6 & 1.5 & 1.8 & - & - \\
\hline Chlorogenic acid der. 12 & 20.8 & 1.5 & 1.6 & - & - \\
\hline Chlorogenic acid der. 13 & 21.3 & 4.2 & 1.8 & 1.0 & 0.7 \\
\hline Chlorogenic acid der. 14 & 21.7 & 7.4 & 3.3 & 0.6 & 0.9 \\
\hline Chlorogenic acid der. 15 & 22.2 & 76.3 & 59.5 & 18.7 & 19.2 \\
\hline Chlorogenic acid der. 16 & 22.6 & 49.1 & 36.4 & 9.2 & 9.8 \\
\hline Caffeic acid der. 3 & 24.9 & 1.5 & 1.0 & 0.4 & 0.3 \\
\hline Chlorogenic acid der. 17 & 25.2 & 9.6 & 7.9 & 2.0 & 2.2 \\
\hline Chlorogenic acid der. 18 & 25.9 & 72.8 & 58.0 & 13.8 & 15.7 \\
\hline Caffeic acid der. 4 & 28.4 & 1.0 & 1.0 & 0.1 & 0.2 \\
\hline Chlorogenic acid der. 19 & 29.5 & 9.6 & 8.9 & 1.4 & 2.0 \\
\hline Chlorogenic acid der. 20 & 32.5 & 4.1 & 4.7 & - & - \\
\hline Total of cinnamates & - & 3240 & 2680 & 308 & 322 \\
\hline
\end{tabular}


The coffee samples consisted of hydroxycinnamates, which were mainly different derivatives of chlorogenic acid (caffeoylquinic acids) and ferulic acid, but also the derivatives of caffeic and $p$-hydroxycinnamic acid. Additionally, one of the main components in the samples was the methylxanthine alkaloid, caffeine.

Recently, Martínez et al. (2017) established that chlorogenic acid inhibits mycelial growth and spore germination at doses of $15 \mu \mathrm{g} / \mu \mathrm{L}$ against phytopathogenic fungi relevant in horticulture and agriculture. Chlorogenic acid has been known to be abundantly available in industrial by-products, such as those derived from coffee (Murthy and Naidu 2012). The recovered phenolic components have mostly been considered for new valueadded products, such as phenolic antioxidant adjunct for food processing, but not for wood preservation.

Caffeic and protocatechuic acids have been found to completely inhibit the growth of two Aspergillus spp. molds at concentrations of $0.2 \mathrm{mg} / \mathrm{mL}$ and $0.3 \mathrm{mg} / \mathrm{mL}$ (Aziz et al. 1998). Cinnamic acid and its derivatives have been shown to inhibit the growth of Candida albicans and A. niger at low doses (Narasimhan et al. 2004). Also, caffeic, chlorogenic, ferulic, and trans-cinnamic acids have recently been reported to prevent the activity of several Colletotrichum spp. isolates that cause anthracnose fruit rot (Roy et al. 2018).

The proportions of the compounds were similar between the two fresh coffee samples and between the two SCEs samples. The compound amounts were highest in the fresh coffee sample. Filtration of the fresh coffee reduced the concentrations of the compounds, and thus the amount of cinnamic acids and caffeine in the filtered fresh coffee sample was $17 \%$ and $15 \%$ lower, respectively, than in the unfiltered sample. In SCEs, the difference in the total cinnamates between the filtered and unfiltered samples was approximately $4 \%$.

The SCEs inhibited the growth of the four species of decay fungi when applied at concentrations of 1\% and higher (Fig. 1). Arora and Ohlan (1997) concluded that 0.5\% caffeine fully inhibits fungal growth. The highest concentration (w/w) of SCEs in this study was $5 \%$, which indicated the presence of less than $0.1 \%$ caffeine. These findings agreed with those of Arora and Ohlan (1997) but showed a stronger effect on G. trabeum compared with pure caffeine. This indicated that there are synergistic effects between the chemicals in spent coffee grounds that prevent the growth of wood-decaying fungi.

Filtering the SCEs caused a significant increase in the inhibition of C. puteana, $G$. trabeum, and T. versicolor (see Fig. 2 for a practical example). Arora and Ohlan (1997) found that filtering the coffee decreased its antifungal effect by $53 \%$. This decrease in effectiveness of the spent coffee when filtered may have been caused by the presence of other chemicals, such as carbohydrates, that promote fungal growth and hinder the antifungal activity of other chemicals.

A preliminary test was done based on the same method, but with $0.2 \%$ spent coffee in the media. This test promoted the growth of G. trabeum (data not shown), which supported the conclusion that there are chemicals present in the SCEs that promote the growth of fungi. For $C$. puteana and $R$. placenta, the inhibition caused by $1 \%$ fresh coffee did not differ significantly from that of the spent 5\% SCEs. However, compared with the other species, $1 \%$ fresh coffee caused the highest inhibition, which differed significantly from that of the other concentrations. These differences indicated that chemicals present in fresh coffee and not spent coffee can play a role in fungal inhibition. The medium with $1.6 \%$ copper-based preservative completely inhibited the growth of all of the fungi. 


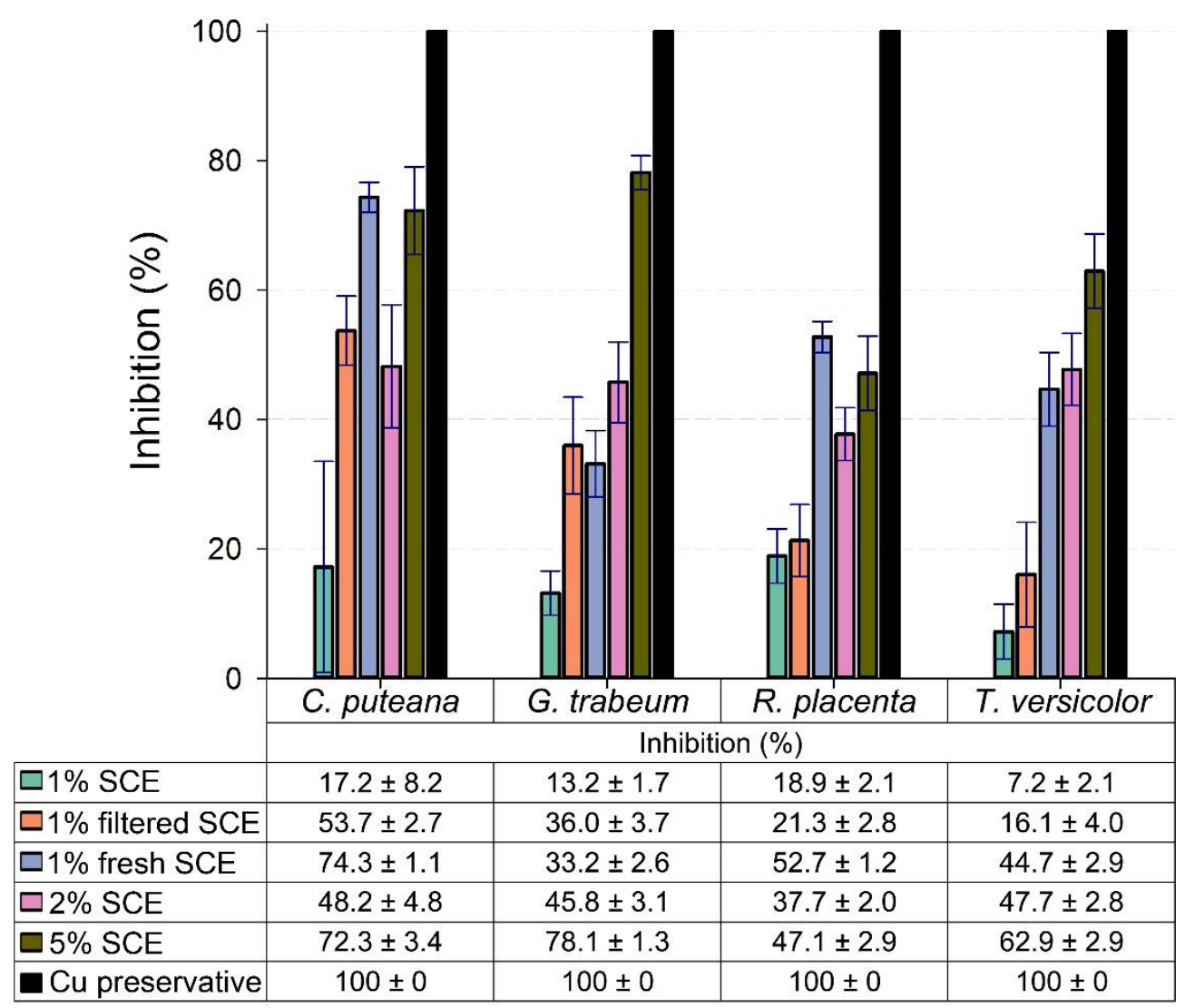

Fig. 1. Inhibition of wood-decaying fungi by fresh and spent coffee ground extracts: $C$. puteana, G. trabeum, and R. placenta $(\mathrm{N}=10)$, and T. versicolor $(\mathrm{N}=6)$

The statistical analysis confirmed that all the SCEs inhibited significantly $(P=0.000)$ the growth of all species of fungi when compared to reference media. Fresh coffee caused a significantly higher inhibition than spent coffee in all fungi $(P=0.000)$ and filtering of $1 \%$ SCEs caused significant growth inhibition in all fungi $(P<0.05)$ except $R$. placenta when compared to $1 \%$ SCE.
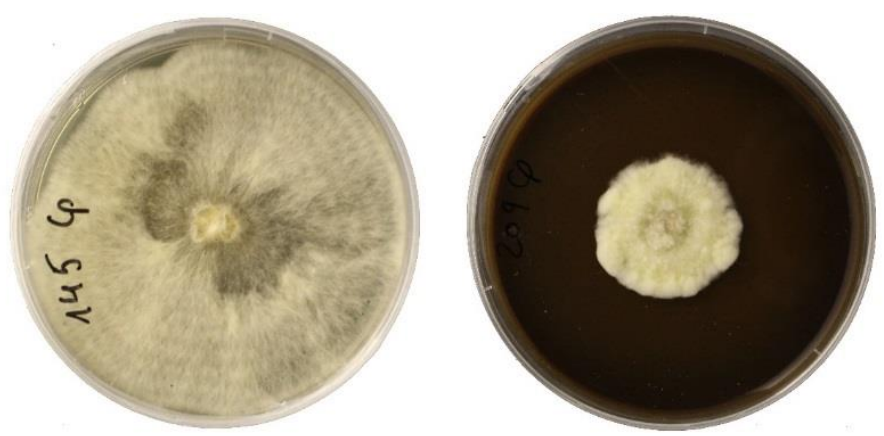

Fig. 2. Growth of C. puteana (BAM 112) after $13 \mathrm{~d}$ in malt-agar media petri dish with the control on the left and the $5 \%$ non-filtered spent coffee ground extract infused media on the right

During the experiment, a decolorized halo around the mycelia of $C$. puteana was observed after $4 \mathrm{~d}$ to $5 \mathrm{~d}$, which could have indicated that compounds were released by the fungi that detoxified the growth media. This was similar to the results reported by Kovačec et al. (2017). 
The minimum inhibitory concentration (MIC) to completely inhibit the growth of fungi was not determined, but the results showed that the MIC value was beyond $5 \%$ for all of the fungi tested. This meant that spent coffee is not a feasible wood preservative, but it could be considered a green source of chemicals that can contribute to preservative formulations against fungi after selective separation and purification. Recent studies have also found a high antioxidant activity in SCEs (Panusa et al. 2013) that is often related to the natural durability of wood (Binbuga et al. 2008) and may enhance the potential for the use of these extracts in wood preservative formulations.

The antifungal activity of the SCEs against wood-decaying fungi was thus because of the caffeine, as well as several identified antifungal chemicals, such as chlorogenic acid and ferulic acid derivatives and caffeic and $p$-hydroxycinnamic acids. These two sets of chemicals suggested that there is a joint interaction with microbes and that those components contribute to the decay resistance. Furthermore, previous studies have found that low doses of some of the constituents of spent coffee inhibit different kinds of fungi (Aziz et al. 1998; Narasimhan et al. 2004; Lekounougou et al. 2007). Alternative extraction methods of spent coffee ground constituents, their selective separation, and further use in wood preservative formulations may lead to novel methods for the use of bio-based chemicals that can substitute current fungicides.

Recent investigations have presented spent coffee grounds as a useful substrate for the cultivation of wood-degrading fungi that form edible mushrooms (Leifa et al. 2001). In contrast, the findings in this paper showed that several extractives with antifungal activities against wood-decaying fungi remain in coffee grounds after they are used for making coffee. Fan et al. (2006) found that even if the fungus Pleurotus ostreatus still fructified when grown with tannins and caffeine, increasing the concentrations of these chemicals caused reductions in the mycelial growth of the fungus. Their study also found that the tannins were completely degraded, while the caffeine was only partially degraded and accumulated in the mycelium and fruiting bodies of P. ostreatus. Oh et al. (2018) found that the mycelial growth of edible mushrooms decreased when coffee hydrolysates were present in the media, but the antioxidant properties were improved and the number of polyphenols of the mycelia increased. Extraction and selective removal of green chemicals with an antifungal activity as a first step could lead to a better performance of the solid fraction of spent coffee as a media for mushroom cultivation. For this application, both the chemical recovery and mushroom cultivation need to be studied further.

Until recently, SCG has been discarded to landfills and considered solid waste with low value. The commercial viability spent coffee ground chemicals will strongly depend on availability of spent coffee grounds. The coffee industry generates large volumes of wet SCGs from the manufacture of instant coffee and caffeinated drinks (Pfluger 1975), and utilization of this resource is still a rather original and environmentally friendly approach of international and societal interest, avoiding the disposal of such residue in landfills (Stylianou et al.2018). Collecting the waste from private users may not be a feasible option, but collecting the SCGs from the coffee industry is a clear opportunity for its valorization.

\section{CONCLUSIONS}

1. We demonstrated that spent coffee ground extracts contain chemicals that inhibit the growth of wood-decaying fungi at low concentrations. To extract and isolate antifungal 
components from spent coffee grounds has high potential for developing green preservatives and promoting the valorization of organic residues.

2. It was found that the antifungal activity was not solely derived from the presence of caffeine, but also from the synergistic reactivity of the cinnamates and alkaloids that were present in the residue at reasonable concentrations.

\section{ACKNOWLEDGMENTS}

This work was supported by the KAUTE Foundation and Teollisuusneuvos Heikki Väänänen's Fund.

\section{REFERENCES CITED}

Acevedo, F., Rubilar, M., Scheuermann, E., Cancino, B., Uquiche, E., Garcés, M., Inostroza, K., and Shene, C. (2013). "Spent coffee grounds as a renewable source of bioactive compounds," J. Biobased Mater. Biol. 7(3), 420-428.

DOI: 10.1166/jbmb.2013.1369

Ancin-Murguzur, F. J. Barbero-López, A., Kontunen-Soppela, S., and Haapala, A. (2018). "Automated image analysis tool to measure microbial growth on solid cultures", Comput. Electron. Agric. 151, 426-430. DOI:

10.1016/j.compag.2018.06.031

Anttila, A.-K., Pirttilä, A. M., Häggman, H., Harju, A., Venäläinen, M., Haapala, A., Holmbom, B., and Julkunen-Tiitto, R. (2013). "Condensed conifer tannins as antifungal agents in liquid culture," Holzforschung 67(7), 825-832.

DOI: $10.1515 / \mathrm{hf}-2012-0154$

Arora, D. S., and Ohlan, D. (1997). "In vitro studies on antifungal activity of tea (Camellia sinensis) and coffee (Coffea arabica) against wood-rotting fungi," J. Basic Microb. 37(3), 159-165. DOI: 10.1002/jobm.3620370302

Aziz, N. H., Farag, S. E., Mousa, L. A. A., and Abo-Zaid, M. A. (1998). "Comparative antibacterial and antifungal effects of some phenolic compounds," Microbios. 93(374), 43-54.

Binbuga, N., Ruhs, C., Hasty, J. K., Henry, W. P., and Schultz, T. P. (2008). "Developing environmentally benign and effective organic wood preservatives by understanding the biocidal and non-biocidal properties of extractives in naturally durable heartwood," Holzforschung 62(3), 264-269. DOI: 10.1515/HF.2008.038

Chang, S.-T., Wang, S.-Y., Wu, C.-L., Su, Y.-C., and Kuo, Y.-H. (1999). “Antifungal compounds in the ethyl acetate soluble fraction of the extractives of Taiwania (Taiwania cryptomerioides Hayata) heartwood," Holzforschung 53(5), 487-490. DOI: 10.1515/HF.1999.080

Ding, T., Bianchi, S., Ganne-Chédeville, C., Kilpeläinen, P., Haapala, A., and Räty, T. (2017). "Life cycle assessment of tannin extraction from spruce bark," iForest 10(5), 807-814. DOI: 10.3832/ifor2342-010

Fan, L., Soccol, A. T., Pandey, A., de Souza Vandenberghe, L. P., and Soccol, C. R. (2006). "Effect of caffeine and tannins on cultivation and fructification of Pleurotus on coffee husks," Braz. J. Microbiol. 37(4), 420-424. 
DOI: $10.1590 / \mathrm{S} 1517-83822006000400003$

Geissen, V., Mol, H., Klumpp, E., Umlauf, G., Nadal, M., van der Ploeg, M., van de Zee, S. E. A. T. M., and Ritsema, C. J. (2015). "Emerging pollutants in the environment: A challenge for water resource management," Int. Soil Water Conserv. Res. 3(1), 57-65. DOI: $10.1016 /$ j.iswcr.2015.03.002

Koloverou, E., Panagiotakos, D. B., Pitsavos, C., Chrysohoou, C., Georgousopoulou, E. N., Laskaris, A., and Stefanadis, C. (2015). "The evaluation of inflammatory and oxidative stress biomarkers on coffee-diabetes association: Results from the 10-year follow-up of the ATTICA Study (2002-2012)," Eur. J. Clin. Nutr. 69(11), 12201225. DOI: $10.1038 /$ jen.2015.98

Kookos, I. K. (2018). "Technoeconomic and environmental assessment of a process for biodiesel production from spent coffee grounds (SCGs)," Res. Con. Recyc, 134, 156164.

Kourmentza, C., Economou, C. N., Tsafrakidou, P., and Kornaros, M. (2018). "Spent coffee grounds make much more than waste: Exploring recent advances and future exploitation strategies for the valorization of an emerging food waste stream," $J$. Clean Prod. 172, 980-992. DOI: 10.1016/j.jclepro.2017.10.088

Kovačec, E., Regvar, M., van Elteren, J. T., Arčon, I., Papp, T., Makovec, D., and VogelMikuš, K. (2017). "Biotransformation of copper oxide nanoparticles by the pathogenic fungus Botrytis cinerea," Chemosphere 180, 178-185.

DOI: 10.1016/j.chemosphere.2017.04.022

Lekounougou, S., Ondo, J. P., Jacquot, J., Nevers, G., Gérardin, P., and Gelhaye, E. (2007). "Effects of caffeine on growth of wood-decaying fungi," in: The International Research Group on Wood Protection, Stockholm, Sweden.

Leifa, F., Pandey, A. and Soccol, C. R. (2001). "Production of Flammulina velutipes on coffee husk and coffee spent-ground," Braz. Arch. Biol. Technol. 44, 205-212. DOI: 10.1590/S1516-89132001000200015

Lu, J., Venäläinen, M., Julkunen-Tiitto, R., and Harju, A. M. (2016). "Stilbene impregnation retards brown-rot decay of Scots pine sapwood," Holzforschung 70(3), 261-266. DOI: $10.1515 / \mathrm{hf}-2014-0251$

Martínez, G., Regente, M., Jacobi, S., Del Rio, M., Pinedo, M., and de la Canal, L. (2017). "Chlorogenic acid is a fungicide active against phytopathogenic fungi," Pestic. Biochem. Phys. 140, 30-35. DOI: 10.1016/j.pestbp.2017.05.012

Mata, T. M., Martins, A. A., and Caetano, N. S. (2018). "Bio-refinery approach for spent coffee grounds valorization," Bioresour. Technol. 247, 1077-1084. DOI: 10.1016/j.biortech.2017.09.106

Mazela, B., Cofta, G., Perdoch, W., Gobakken, L. R., and Kwaśniewska-Sip, P. (2016). "Decay resistance of wood treated with bio-friendly preservative systems," in: $47^{\text {th }}$ IRG Annual Meeting, Lisbon, Portugal.

Mohajerani, A., Vajna, J., and Ellcock, R. (2018). "Chromated copper arsenate timber: A review of products, leachate studies and recycling," J. Clean Prod. 179, 292-307. DOI: $10.1016 / \mathrm{j}$.jclepro.2018.01.111

Monente, C., Ludwig, I. A., Irigoyen, A., De Peña, M.-P., and Cid, C. (2015). "Assessment of total (free and bound) phenolic compounds in spent coffee extracts," J. Agr. Food Chem. 63(17), 4327-4334. DOI: 10.1021/acs.jafc.5b01619

Mullen, W., Nemzer, B., Stalmach, A., Ali, S., and Combet, E. (2013). "Polyphenolic and hydroxycinnamate contents of whole coffee fruits from China, India, and Mexico," $J$. Agr. Food Chem. 61(22), 5298-5309. DOI: 10.1021/jf4003126 
Murthy, P. S., and Naidu, M. M. (2012). "Recovery of phenolic antioxidants and functional compounds from coffee industry by-products," Food Bioprocess Tech. 5(3), 897-903. DOI: 10.1007/s11947-010-0363-z

Narasimhan, B., Belsare, D., Pharande, D., Mourya, V., and Dhake, A. (2004). "Esters, amides and substituted derivatives of cinnamic acid: Synthesis, antimicrobial activity and QSAR investigations," Eur. J. Med. Chem. 39(10), 827-834.

DOI: 10.1016/j.ejmech.2004.06.013

Oh, N.-S., Sung, N.-Y., Byun, E.-H., Kim, Y.-E., Cho, E.-J., and Oh, C.-H. (2018). "Changes in mycelial growth and antioxidant activities of basidiomycetous strains added with hydrolysates of spent coffee grounds as a substrate," J. Korean Soc. Food Sci. Nutr. 47(1), 90-95. DOI: 10.3746/jkfn.2018.47.1.090

Panusa, A., Zuorro, A., Lavecchia, R., Marrosu, G., and Petrucci, R. (2013). "Recovery of natural antioxidants from spent coffee grounds," J. Agr. Food Chem. 61(17), 41624168. DOI: 10.1021/jf4005719

Panzella, L., Pérez-Burillo, S., Pastoriza, S., Martín, M. Á., Cerruti, P., Goya, L., Ramos, S., Rufián-Henares, J. A., Napolitano, A., and d'Ischia, M. (2017). "High antioxidant action and prebiotic activity of hydrolyzed spent coffee grounds (HSCG) in a simulated digestion-fermentation model: Toward the development of a novel food supplement," J. Agr. Food Chem. 65(31), 6452-6459. DOI: 10.1021/acs.jafc.7b02302

Pfluger, R. A. (1975). "Soluble coffee processing," in: Solid wastes: origin, collection, processing, and disposal, C. L. Mantell (ed.), New York: Wiley.

Ricketts, T. H., Daily, G. C., Ehrlich, P. R., and Michener, C. D. (2004). "Economic value of tropical forest to coffee production," P. Natl. Acad. Sci. USA 101(34), 12579-12582. DOI: 10.1073/pnas.0405147101

Roy, S., Nuckles, E., and Archbold, D. D. (2018). "Effects of phenolic compounds on growth of Colletotrichum spp. in vitro," Curr. Microbiol. 75(5), 550-556. DOI: $10.1007 / \mathrm{s} 00284-017-1415-7$

Sant'Anna, V., Biondo, E., Kolchinski, E. M., da Silva, L. F. S., Corrêa, A. P. F., Bach, E., and Brandelli, A. (2017). "Total polyphenols, antioxidant, antimicrobial and allelopathic activities of spend coffee ground aqueous extract," Waste Biomass Valori. 8(2), 439-442. DOI: 10.1007/s12649-016-9575-4

Santos, C., Fonseca, J., Aires, A., Coutinho, J., and Trindade, H. (2017). "Effect of different rates of spent coffee grounds (SCG) on composting process, gaseous emissions and quality of end-product," Waste Manage. 59, 37-47.

DOI: 10.1016/j.wasman.2016.10.020

Sousa, C., Gabriel, C., Cerqueira, F., Manso, M. C., and Vinha, A. F. (2015). “Coffee industrial waste as a natural source of bioactive compounds with antibacterial and antifungal activities," in: The Battle Against Microbial Pathogens: Basic Science, Technological Advances and Educational Programs, A. Méndez-Vilas (ed.), Formatex Research Center, Badajoz, Spain, pp. 131-136.

Stylianou, M., Agapiou, A., Omirou, M., Vyrides, I., Ioannides, I. M., Maratheftis, G., and Fasoula, D. (2018). "Converting environmental risks to benefits by using spent coffee grounds (SCG) as a valuable resource," Environ Sci Pollut Res, 1-15. DOI: 10.1007/s11356-018-2359-6

Article submitted: April 20, 2018; Peer review completed: June 28, 2018; Revised version received and accepted: July 9, 2018; Published: July 11, 2018.

DOI: $10.15376 /$ biores.13.3.6555-6564 